\title{
The evaluation on a mobile augmented reality application as therapy media
}

\author{
Hendra Pradibta ${ }^{1}$, Indra Dharma Wijaya $^{1}$, Ferdian Ronilaya ${ }^{2}$, and Usman Nurhasan ${ }^{1}$ \\ ${ }^{1}$ State Polytechnic of Malang, Information Technology, Malang \\ ${ }^{2}$ State Polytechnic of Malang, Electrical Engineering, Malang
}

\begin{abstract}
ARdoa is Mobile Augmented Reality (MAR) application used as a therapy media for children with Autism Spectrum Disorder (ASD). The content of this application is daily prayers for Muslim children, and it is designed in the form of audio-video animation. This paper is aimed at discussing the evaluation and testing of the development process of MAR ARdoa. Technical evaluation and testing are conducted on several aspects, specifically testing the detection and tracking. Moreover, the method used in the process is to identify the distance, surface area and ideal conditions for the utilization of this application. The completion of the test is based on whether or not the content appearing on the marker has been made. From the evaluation and testing process, it is obtained ideal distance, surface area and conditions for the utilization of MAR ARdoa that can be used as standards for its development.
\end{abstract}

\section{Introduction}

Technology has a great potential to be used as a tool in the provision of support in the field of education for people with ASD [1]. Some researchers have been undertaken as part of the development and support for people with ASD, in form of games [2], [3] interactive visual support applications [4] as well as other supporting applications [5], [6], [7], [8], [9]. Of some developed applications, most of them are mobile-based applications. With its ubiquitous, mobile technology especially mobile phones and tablets is expected to be one of the tools in the treatment of children with ASD [10]

Augmented Reality (AR) is an application that can combine virtual objects in the real world [11]. AR has a great potential to attract, inspire, and motivate users to explore and controlling of different perspectives [12]. Hopefully, MAR Ardoa can be used as an alternative therapy media and enrichment for therapy media for children with ASD. This study discusses the testing of MAR Ardoa [13] of some technical aspects. The purpose of this test is to identify how to apply an ideal MAR Ardoa technically.

\section{Supporting theory}

Methods tests applied in this study are adapted to those proposed by Ibanez and Figures [14]. The tests are based on the capabilities of a device (smartphone) in identifying the target image and displaying the content that has been created.

The first test is done by testing MAR Ardoa on the device (smartphone). The next test is a test based on the rating target image obtained on the web vuforia, wherein an image the target rating indicates whether or not a marker is detected by all the AR system [15]. The next test is the test for the detection. This process is performed to determine the ability of the application to recognize the target image. Some of the tests performed are time, distance, and surface area range testing.

\section{Testing methods}

\subsection{Testing device}

The testing methods are adapted to the methods proposed by Ibanez and Figure [14] with some additions, focused in detection characteristics. MAR Ardoa prototype is tested using three smartphones with different specifications. The two smartphones, i.e. Xiaomi redmi 4x and Samsung J5 Prime have similar specifications; whereas, Andromax, has lower specifications. This kind of testing is conducted in order to examine the effects of the device specifications used for Ardoa application.

Table 1. Device specifications.

\begin{tabular}{|l|l|}
\hline \multicolumn{1}{|c|}{ Device } & \multicolumn{1}{c|}{ Specifications } \\
\hline $\begin{array}{l}\text { Xiaomi } \\
\text { redmi 4x }\end{array}$ & CPU Octa Core 1.4 GHz Cortex 435 \\
& Android 6.0.1 (Marshmallow) \\
& Chipset Qualcomm Snapdragon 435 \\
& Camera 13 MP \\
& Ram 3 GB \\
& 5-inch, 720x1280 pixels \\
\hline $\begin{array}{l}\text { Samsung J5 } \\
\text { Prime }\end{array}$ & CPU Quad Core 435 1.4 GHz Cortex \\
& Android 6.0.1 (Marshmallow) \\
& Chipset Exynos 7570 Quad \\
\hline
\end{tabular}

\footnotetext{
* Corresponding author: hendra.pradibta $@$ polinema.ac.id
} 


\begin{tabular}{|c|l|}
\hline Device & \multicolumn{1}{|c|}{ Specifications } \\
\hline & Camera 13 MP \\
& Ram 2 GB \\
& 5-inch, 720x1280 pixels \\
\hline Andromax A & CPU Quad-core 1.1 GHz Cortex A7 \\
& Android 5.0 Lollipop \\
& Chipset Qualcomm MSM8909 Snapdragon \\
& 210 \\
& 5MP Camera \\
& Ram1 GB \\
& 4.5-inch, 480x800 pixels \\
\hline
\end{tabular}

MAR Ardoa is installed on the three devices described in the table 1 above, and it is found out that all three devices can run the application smoothly without any interruptions. Although all three of these devices have differences on RAM specifications, camera, and the screen, the results displayed by those three can be said to run in accordance with the needs. Moreover, the contents (prayer before studying, having meals and going to bed) of MAR Ardoa can run smoothly.

For further testing, the testing process is done by using a smartphone that has significantly different specifications. Based on the specifications in the table, then only 2 smartphones used for the testing process are Xiaomi redmi $4 \mathrm{x}$ and Andromax A.

In this test, the marker used is printed on A4 sized paper with an image size of $19.46 \mathrm{~cm} \times 19.92 \mathrm{~cm}$. The printing process is done in Color and Gray Scale settings. Each test is repeated for 3 times, then their average is used as the final result.

\subsection{Image rating target testing}

Testing the target image rating is obtained from the Ardoa target image upload process on Vuforia website.

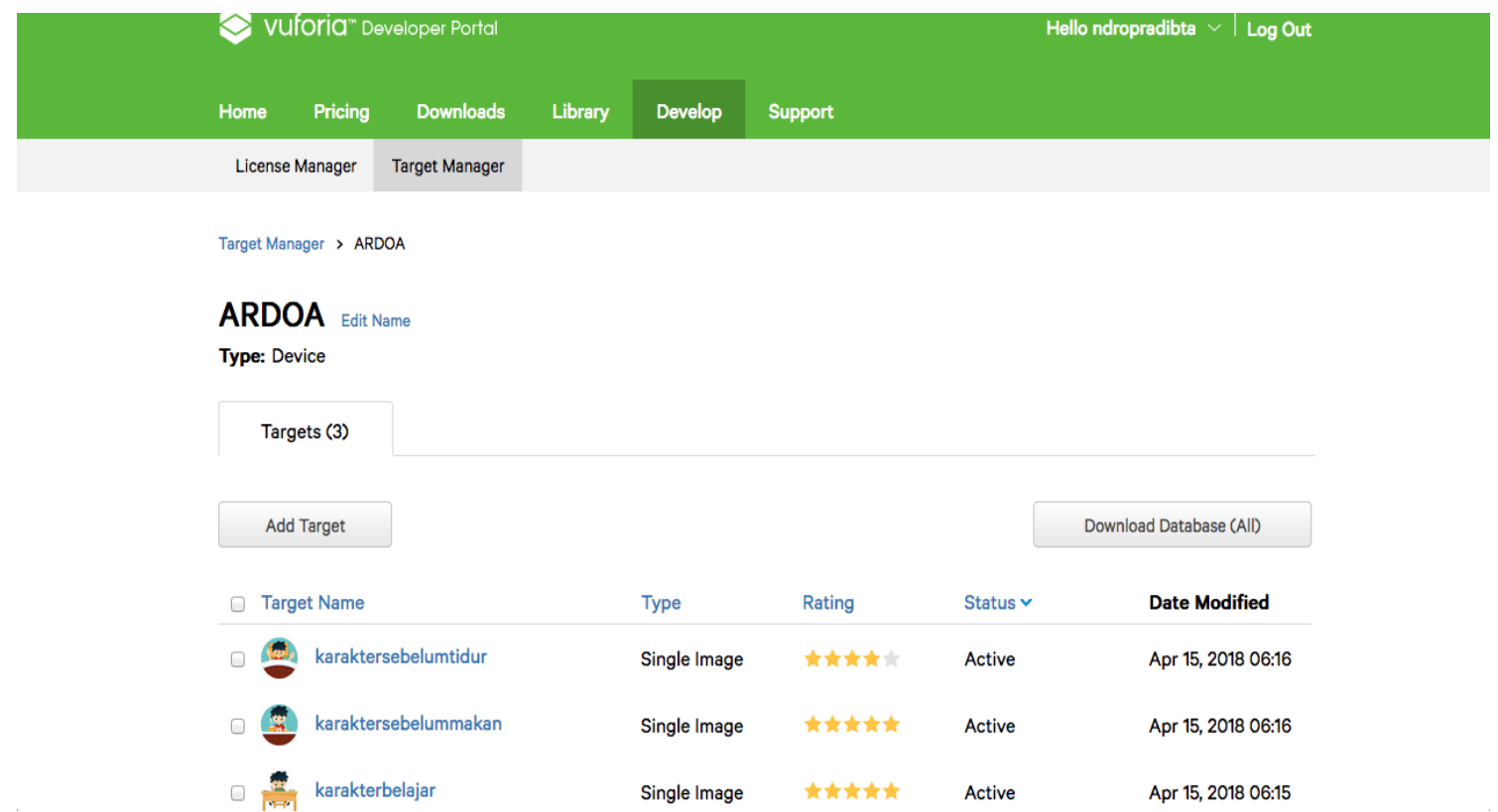

Fig. 1. Image target manager.

The rating number of stars shows a good detection quality. The more the number rating of the star is, the better the image of the target is detected.

Table 2. Image target and rating.

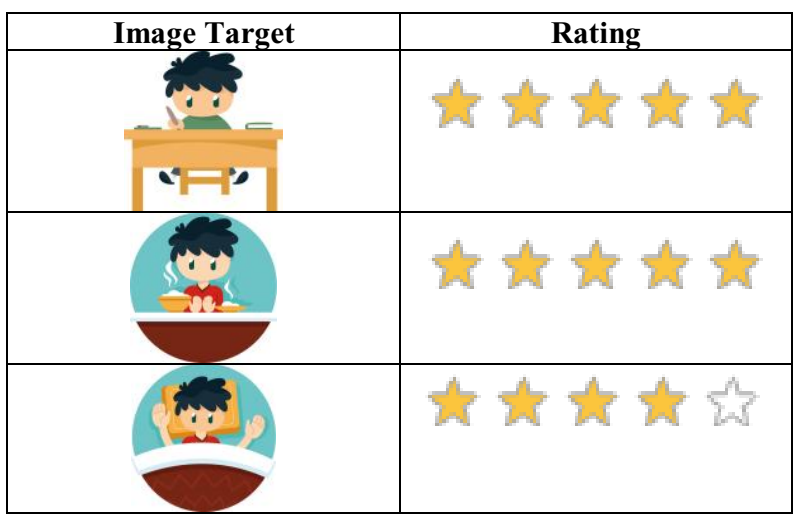

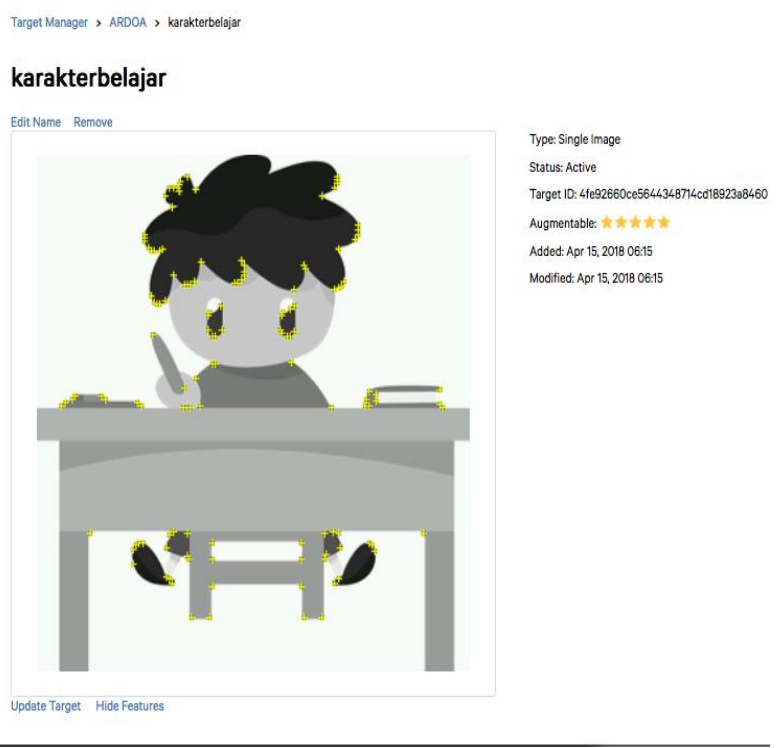

Fig. 2. Feature of studying character. 
Figure 2 showing a studying character, and from the results shows the 5-star rating. Thus, it can be concluded that the image marker that is used for this character has good details. It can be seen from the picture that there are a lot of features showing points.

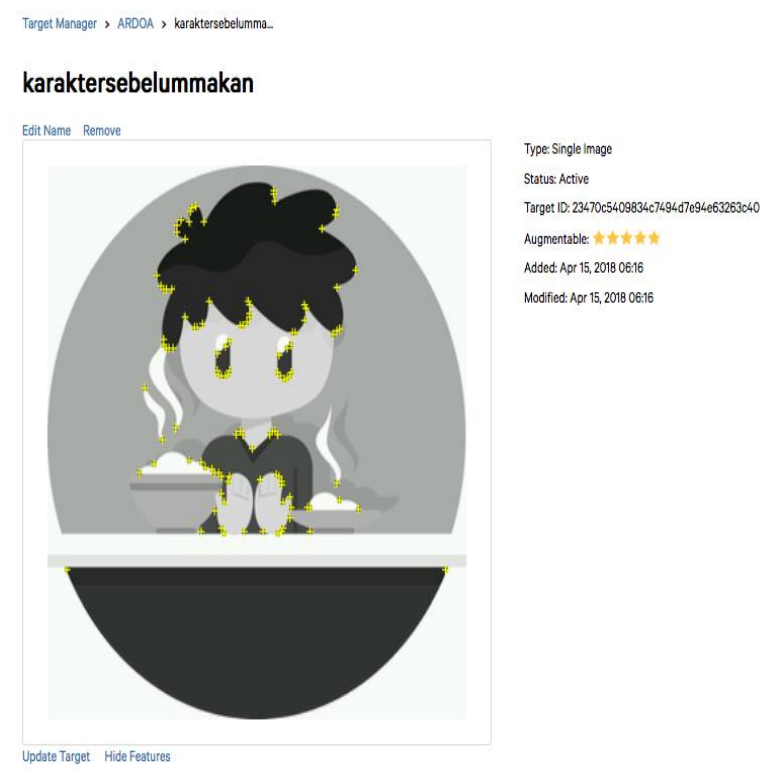

Fig. 3. Feature of before having meal character.

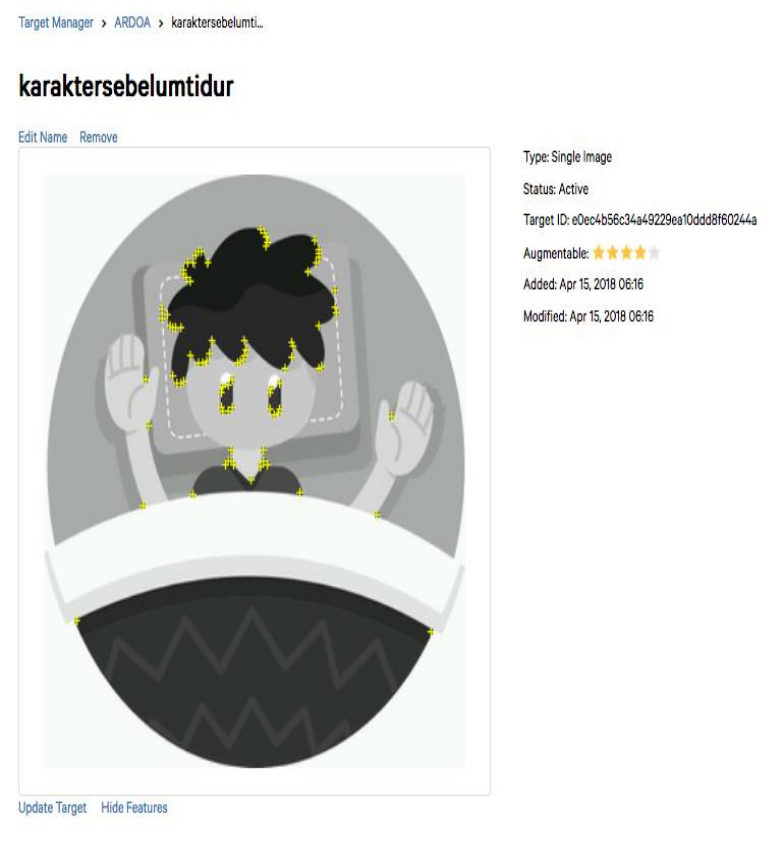

Fig. 4. Feature of before going to bed character.

\subsection{Testing the detection of}

\subsubsection{Testing of color printing}

The detection testing is done by printing the target image on A4 sized paper with the target image size of $19,46 \mathrm{~cm}$ $\mathrm{x} 19,92 \mathrm{~cm}$. The printing is done in color and grayscale color settings. The test results show that in the color and grayscale color settings, both devices can display the contents contained in the target image both with and without any constraint. For the subsequent testing process, the target image used is the target image in grayscale color settings.

\subsubsection{Testing of detection time}

The detection time testing is conducted to determine the time required for the smartphone to recognize the target image created. The testing is done by opening the MAR Ardoa on the smartphone, then directing its camera at a particular target image. The test is considered successful if the target image can display the contents according to the target image. From the early detection testing process of the target image, it is obtained that the average time is $<2$ seconds for all devices.

Table 3. Detection time testing.

\begin{tabular}{|c|c|}
\hline Device & The average time \\
\hline Xiaomi redmi 4x & $<2$ seconds \\
\hline Andromax A & $<2$ seconds \\
\hline
\end{tabular}

\subsubsection{Testing of the minimum distance detection}

The testing of minimum distance detection is conducted to obtain the minimum distance the device in recognizing the target image. The testing process is done by putting the target image at its farthest distance then continually the smartphone approaches the target image. The test is considered successful if the smartphone can detect the target image.

Table 4. Minimum distance detection testing.

\begin{tabular}{|c|c|}
\hline Device & $\begin{array}{c}\text { The average } \\
\text { distance }\end{array}$ \\
\hline $4 \mathrm{x}$ Xiaomi redmi & $100 \mathrm{~cm}$ \\
\hline Andromax A & $68 \mathrm{~cm}$ \\
\hline
\end{tabular}

\subsubsection{Testing of surface area}

The testing process is done by covering a specific area of the target image with the parameters of $25 \%, 50 \%$, and $75 \%$. Moreover, it is done by dividing the target image by folding it into 4 parts.

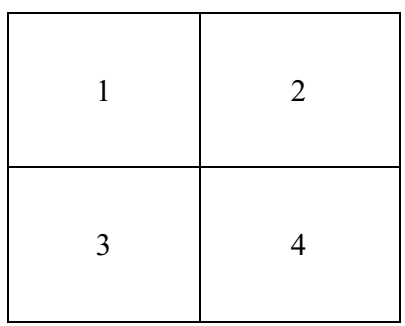

Fig. 5. The distribution of surface area.

Later in the process of the surface area testing, the paper is folded and scanned using the smartphone. The test is considered successful if the smartphone can detect the target image and audio content display the corresponding video. 
Table 5. The surface area covered.

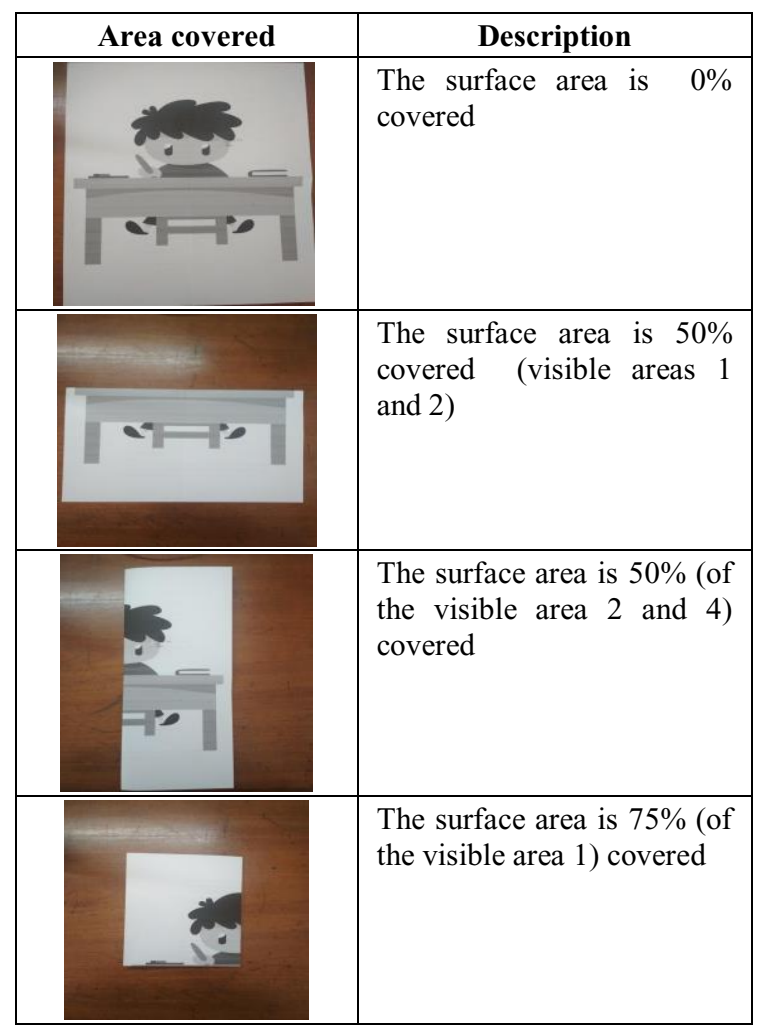

Table 6. The surface area of studying character.

\begin{tabular}{|c|c|c|}
\hline $\begin{array}{c}\text { Covered } \\
\text { area }\end{array}$ & Status & Description \\
\hline $25 \%$ & emerging & $\begin{array}{c}\text { Image targets can be } \\
\text { detected }\end{array}$ \\
\hline $50 \%$ & emerging & $\begin{array}{c}\text { Image targets can be } \\
\text { detected }\end{array}$ \\
\hline $75 \%$ & emerging & $\begin{array}{c}\text { Image targets can be } \\
\text { detected }\end{array}$ \\
\hline
\end{tabular}

Table 7. The surface area of before having a meal character.

\begin{tabular}{|c|c|c|}
\hline $\begin{array}{c}\text { Covered } \\
\text { area }\end{array}$ & Status & Description \\
\hline $25 \%$ & $\begin{array}{c}\text { emerging / } \\
\text { no }\end{array}$ & $\begin{array}{c}\text { In area 1, 2, the content } \\
\text { appears, while area 3, 4 } \\
\text { content cannot appear }\end{array}$ \\
\hline $50 \%$ & emerging & $\begin{array}{c}\text { Image targets can be } \\
\text { detected }\end{array}$ \\
\hline $75 \%$ & emerging & $\begin{array}{c}\text { Image targets can be } \\
\text { detected }\end{array}$ \\
\hline
\end{tabular}

Table 8. The surface area of before going to bed character.

\begin{tabular}{|c|c|c|}
\hline Covered Area & Status & Description \\
\hline $25 \%$ & cannot appear & $\begin{array}{c}\text { In 3 and } 4 \text { area, the } \\
\text { contents cannot } \\
\text { appear }\end{array}$ \\
\hline $50 \%$ & appear/can not & $\begin{array}{c}\text { In } 3 \& 4 \text { area, the } \\
\text { content cannot } \\
\text { appear, while the } \\
\text { content } 1 \text { \& } 2 \text { content } \\
\text { can appear }\end{array}$ \\
\hline $75 \%$ & appear & $\begin{array}{c}\text { the image target can } \\
\text { be detected }\end{array}$ \\
\hline
\end{tabular}

\section{Conclusion}

Based on the results of testing that has been done, it can be concluded as follows:

- MAR Ardoa can run well on all three different smartphones. This shows that the difference specification does not provide the difference in the performance of MAR Ardoa.

- The differences from the use of the device (camera) specification are found at the early detection of the target image. It takes a different minimum distance at 2 devices (68 and $100 \mathrm{~cm}$ ). The best distance is use $30-40 \mathrm{~cm}$ (assuming the target image is printed on A4 sized paper)

- The image targets used in MAR Ardoa can be detected well, although with a different color setting. This suggests that whether or not the target image on vuforia rating is not based on color [16], but based on the features contained in the target image.

- The image features also affect the testing process of the surface area [17]. In the particular target image, the closure of the surface area by $75 \%$ causes the target image is not detected, it is because in certain parts $(25 \%$ of which is visible) there are not many image features.

\section{References}

1. L. Escobedo, D. H. Nguyen, L. Boyd, S. Hirano, A. Rangel, D. Garcia-Rosas, M. Tentori, and G. Hayes, "MOSOCO: a mobile assistive tool to support children with autism practicing social skills in real-life situations," Proc. 2012 ACM Annu. Conf. Hum. Factors Comput. Syst., pp. 2589-2598, (2012)

2. S. K. Bhatt, N. I. De Leon, and A. Al-Jumaily, "Augmented Reality Game Therapy for Children with Autism Spectrum Disorder," Int. J. Smart Sens. Intell. Syst., vol. 7, no. 2, pp. 519-536, (2014)

3. Z. Bai and A. F. Blackwell, "See-through window vs. magic mirror: A comparison in supporting visual-motor tasks," 2013 IEEE Int. Symp. Mix. Augment. Reality, ISMAR 2013, no. October, pp. 239-240, (2013)

4. G. R. Hayes, S. Hirano, G. Marcu, M. Monibi, D. H. Nguyen, and M. Yeganyan, "Interactive visual supports for children with autism," Pers. Ubiquitous Comput., vol. 14, no. 7, pp. 663-680, (2010)

5. Z. Bai, A. F. Blackwell, and G. Coulouris, "Making Pretense Visible and Graspable: An augmented reality approach to promote pretend play," in ISMAR 2012 - 11th IEEE International Symposium on Mixed and Augmented Reality 2012, Science and Technology Papers, pp. 267-268. (2012)

6. H. Pradibta, B. Harijanto, and D. W. Wibowo, "Penerapan Augmented Reality Sebagai Alternatif Media Pembelajaran," Smartics, vol. 2, no. 2, pp. 
43-48, (2016)

7. H. Pradibta, "Augmented Reality: Daily Prayers for Preschooler Student," Int. J. Interact. Mob. Technol., vol. 12, no. 1, pp. 151-159, (2018)

8. Z. Bai, "Augmenting imagination for children with autism," Proc. 11th Int. Conf. Interact. Des. Child. - IDC'12, p. 327, (2012)

9. H. Sampath, R. Agarwal, and B. Indurkhya, "Assistive technology for children with autism lessons for interaction design," in Proceedings of the 11th Asia Pacific Conference on Computer Human Interaction - APCHI '13, pp. 325-333. (2013)

10. E. Husni and Budianingsih, "Mobile Applications BIUTIS: Let's Study Vocabulary Learning as a Media for Children with Autism," 4th Int. Conf. Electr. Eng. Informatics (Iceei 2013), vol. 11, no. Iceei, pp. 1147-1155, (2013)

11. R. Azuma, "A survey of augmented reality," Presence Teleoperators Virtual Environ., vol. 6, no. 4 , pp. 355-385, (1997)

12. K. Lee, "Augmented Reality in Education and Training," Link. Res. Pract. to Improv. Learn., vol. 56, no. 2, pp. 13-21, (2012)

13. H. Pradibta, "Designing AR Daily Prayers for Children with ASD," in 2017 International Seminar on Application for Technology of Information and Communication, pp. 100-103. (2017)

14. A. S. Ibañez and J. P. Figueras, "Vuforia v1.5 SDK. Analysis and evaluation of capabilities," (2013)

15. Vuforia, "Optimizing Target Detection and Tracking Stability," Vuforia Developer Library, 2018. [Online]. Available: https://ibrary.vuforia.com/articles/Solution/Optimi zing-Target-Detection-and-Tracking-

Stability.html\#natural. [Accessed: 15-Apr-2018].

16. D. Susanto, A. Basuki, and D. R. Hakim, "Mobile Augmented Reality Untuk Pembelajaran IPA Kelas 7 Kurikulum 2013," Pros. SENTIA 2016, vol. 8, no. 2011, pp. 69-74, (2016)

17. J.-T. Hwang and T.-C. Chu, "3D Building Reconstruction By Multiview Images and the Integrated Application With Augmented Reality," ISPRS - Int. Arch. Photogramm. Remote Sens. Spat. Inf. Sci., vol. XLI-B1, no. July, pp. 1235-1241, (2016) 